\title{
Design and construction of a strain gauge-based dynamometer for a 3-axis cutting force measurement in turning process
}

\author{
M. Rizal ${ }^{1}{ }^{*}$, J.A. Ghani ${ }^{2}$, Husni ${ }^{1}$, Husaini ${ }^{1}$ \\ ${ }^{1}$ Department of Mechanical Engineering, Faculty of Engineering \\ Syiah Kuala University (UNSYIAH) \\ 23111, Darussalam, Banda Aceh, Indonesia \\ *Email: muhrizal@unsyiah.ac.id \\ ${ }^{2}$ Department of Mechanical and Materials Engineering, \\ Faculty of Engineering and Built Environment \\ Universiti Kebangsaan Malaysia \\ 43600, UKM Bangi, Malaysia
}

\begin{abstract}
The cutting force is the most significant information in machining processes for the cutting parameter and tool geometry optimization, machine tool design, machinability testing of new materials and tool condition monitoring systems. This paper develops a strain gauge-based dynamometer for a 3-axis cutting force measurement in turning process. The octagonal rings are utilized as force transducer to develop strain gauge-based dynamometer to measure the cutting force acting on the tip of the tool. A novel geometrical design of the dynamometer structure allowed the standard tool shank of the turning operation to be easily changed without altering the sensor system. The developed dynamometer can perform the cutting force measurement up to $2.9 \mathrm{kN}$ and has a dynamic response of about $766 \mathrm{~Hz}$. The sensitivities were found approximately in the range of $31.3 \times 10^{-3}-172.4 \times 10^{-3} \mathrm{mV} / \mathrm{N}$ and it has a low cross-sensitivity error of below $0.87 \%$. This paper is focus on geometrical design, mathematical and FEM analyses which are significant role in force sensor developed and present an application of low cost sensing method in turning process.
\end{abstract}

Keywords: Dynamometer design; force transducer; cutting force in turning; force measurement; sensors.

\section{INTRODUCTION}

One of the most widely used metal cutting processes in manufacturing industries is turning process. It involves a deformation process, where unwanted material is cut or eliminated from the workpiece to produce a desired geometry of the machined part. The cutting force occurs when the cutting tool cuts the workpiece material. It is the most significant information required in machining processes for tool geometry and cutting parameter optimization, machine tool design, surface roughness and chattering predictions, machinability investigations, fundamental studies of machining performance and also tool condition monitoring systems [1, 2]. Therefore, reliable and accurate measurements of cutting forces are urgently needed.

Recently, many researchers have been used piezoelectric dynamometers to measure the cutting force components during turning process. It is clamped to a machine turret or 
tool post, while the tool shank is mounted on it. The principle of this dynamometer is the detection of pressure by the piezoelectric material used as the main element in the construction of the dynamometer, which is then converted to a proportional electric charge. However, commercial dynamometers are unsuitable for industrial use due to their high cost [3]. The alternative to the measurement of the cutting force is to apply the concept of the elastic deformation of the material. There are two methods for measuring the cutting force in a turning process: one involves the use of a strain gauge directly mounted on a tool shank, while the other involves the use of an octagonal ring transducer for a built dynamometer. In the tool shank method of measurement, strain gauges are mounted on the surface of a standard tool shank to measure the deflection in both the tangential and feed direction [4-6]. Nevertheless, this method can only measure two components of a force and it is not sensitive to small forces. The second method involves the use of an octagonal ring transducer, as reported by Yaldiz and Ünsaçar [7], whereby strain gauges were placed on four octagonal rings, as the transducer, flanked by two plates. Then, a tool holder was positioned perpendicular to the plates. The results obtained showed that the dynamometer can be used to measure a force up to a maximum of 3500 $\mathrm{N}$, while the sensitivity of the system is $\pm 5 \mathrm{~N}$. The values of the cross-sensitivity of the dynamometer for the three directions were calculated within the range of $0.17-0.92 \%$. Panzera et al. [8] also developed a dynamometer using strain gauges that were mounted or fixed inside a square cross-sectional bar which had been welded onto the elastic element. The results obtained showed that the repeatability of the strain gauge dynamometer was $6.8 \%$ for the cutting force, $5.9 \%$ for the feed force and $8.4 \%$ for the thrust force. In addition, the strain on tool shank due to the cutting force can also be measured by the surface acoustic wave (SAW) that was reported by Wang et al. [9]. They stated that the signal results have good agreement to the commercial dynamometer.

The challenge was to design a machine tool structure with the highest stiffness and optimal geometry to ensure the measurement gave a precise reading of the cutting force. Moreover, there had been no discussion on the design using the finite element method (FEM) in previous studies, and there had also been no report explaining the testing of the octagonal ring type of dynamometer in a real machining experiment. Therefore, this study focus on design, analysis and fabrication a strain gauge based dynamometer utilized by the octagonal ring. This dynamometer is capable of measuring the cutting force in 3 -axis components during turning process.

\section{THE COMPONENTS OF CUTTING FORCE IN TURNING PROCESS}

Figure 1 shows the turning process, where the work piece material is held by a chuck in front of the spindle of lathe machine, and is rotated at $n \mathrm{rpm}$. When the tool insert comes in contact with the work piece material, it provides a resistance towards the penetration of the cutting tool during the chip removal. This has to be overcome by means of a force, $F$, which is known as the machining or resultant force. This force is analysed by resolving it into its three components or 3 axes. The active force, $F_{a}$ is formed by the cutting force, $F_{c}$ in the direction of the cutting motion together with the feed force, $F_{f}$. The passive or radial force, $F_{r}$ does not contribute to the power conversion because no motion takes place in its direction between the tool and the work piece. Thus:

$$
F=\sqrt{F_{a}^{2}+F_{r}^{2}}=\sqrt{F_{c}^{2}+F_{r}^{2}+F_{f}^{2}}
$$


and

$$
F_{a}=\sqrt{F_{c}^{2}+F_{f}^{2}}
$$

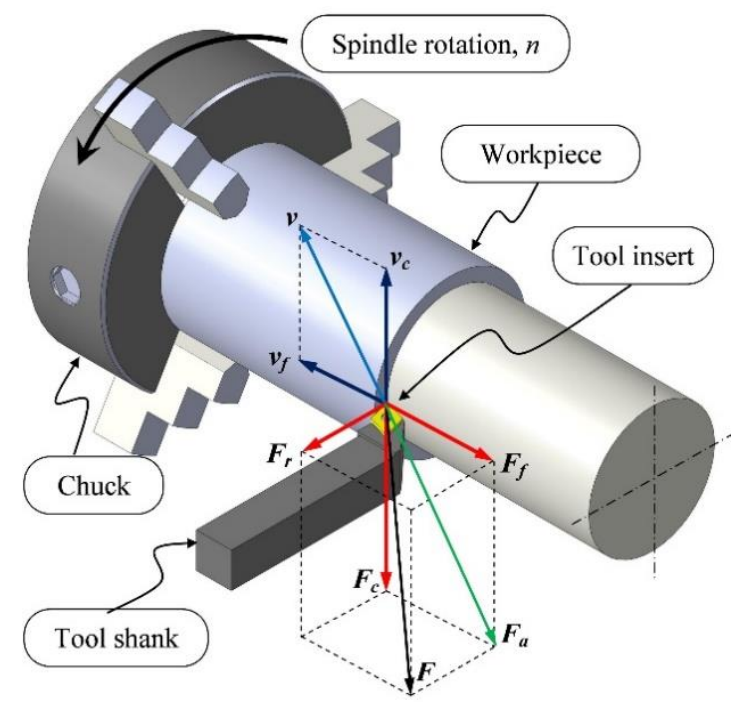

Figure 1. Directions of the cutting force components in a turning operation

\section{STRAIN GAUGE-BASED DYNAMOMETER}

\section{Design and model of force transducer}

The octagonal ring type of force transducer utilizing a strain gauge sensor was selected in this study. The dynamometer was constructed using four octagonal rings that were placed between two plates and fixed with bolts. The bottom plate was used to position the octagonal rings and to hold the dynamometer in the tool post of the lathe machine. Figure 2 illustrates the geometrical design of the octagonal ring force transducer and the components for turning the dynamometer.
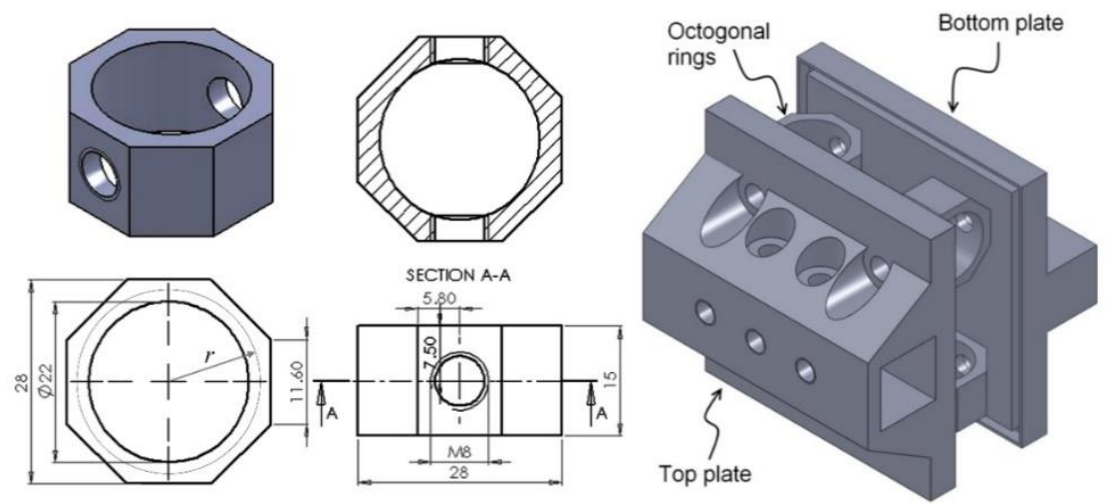

Figure 2. Geometrical design and assembly view of developed dynamometer

The dimensions of the octagonal ring were determined as follows, where the ring width $(b)$ was $15 \mathrm{~mm}$, the ring thickness $(t)$ was $3 \mathrm{~mm}$, and the ring radius $(r)$ was 12.5 $\mathrm{mm}$. The properties of the octagonal rings were defined by their material and design. The selection of the material for the octagonal ring was based on several factors including of the structural rigidity, the maximum force, high natural frequency, mechanical integration, environmental concerns and corrosion resistance. Stainless steel 304 was selected as transducer material because it satisfied the mentioned criteria. The modulus elasticity and Poisson ratio of the material were $193000 \mathrm{~N} / \mathrm{mm}^{2}$ and 0.3 respectively. The 
Brinell hardness was $201 \mathrm{HB}$, and yield and tensile strengths were $205 \mathrm{~N} / \mathrm{mm}^{2}$ and 515 $\mathrm{N} / \mathrm{mm}^{2}$ respectively.

\section{Mathematical analysis of the static properties}

In this study, the octagonal ring was selected as the force transducer in the development of a strain gauge-based dynamometer. This transducer can be simplified as a circular ring which is loaded by two components of force including a horizontal force $\left(F_{h}\right)$ and a vertical force $\left(F_{v}\right)$, as shown in Figure 3. Assuming that the bottom of the ring was fixed and there were external forces acting on the top of ring, the restriction at one end of the ring would cause a moment to occur which varied with the angular position $(\phi)$. The bending moment at different angles in a ring of radius, $r$ from the point of application of the external load was

$$
\begin{array}{ll}
M_{\phi}=\frac{F_{V} r}{2}\left[\frac{2}{\pi}-\sin \phi\right]+\frac{F_{h} r}{2} \cos \phi & 0<\phi<\pi \\
M_{\phi}=\frac{F_{V} r}{2}\left[\frac{2}{\pi}+\sin \phi\right]-\frac{F_{h} r}{2} \cos \phi & \pi<\phi<2 \pi
\end{array}
$$

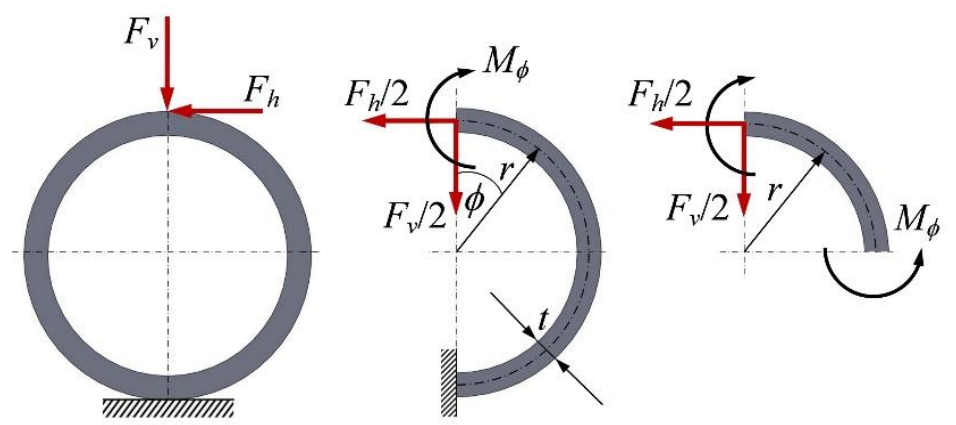

Figure 3. Deformation of a circular ring under vertical and horizontal forces

The deformation of the circular ring occurred when the horizontal force $F_{h}$ and the vertical force $F_{v}$ were applied at the top of the ring. In order to obtain a transducer with a high sensitivity, the strain gauges had to be placed where the stress concentration was at a maximum. In addition, the forces had to be detected in different directions simultaneously and independently, with minimum cross sensitivities or interference errors. For measuring $F_{v}$, the angle of the location of the strain gauge had to be selected in such a way that the bending moment at that angle was only a function of $F_{v}$. Therefore, the second term of equations (3) and (4) had to be zero or could be written as:

$$
\pm \frac{F_{h} r}{2} \cos \phi=0
$$

From Equation (5), $\phi$ was obtained as $90^{\circ}$. Therefore, the strain gauges should be installed at an angle of $\pm 90^{\circ}$ clock wise from the top point of the ring section to measure $F_{v}$ with no interference or side effects from $F_{h}$. In order to measure $F_{h}$, the first term in Equations (3) and (4) had to be equal to zero. Therefore:

$$
\frac{F_{V} r}{2}\left[\frac{2}{\pi} \pm \sin \phi\right]=0
$$

From Equation (6), $\phi$ was calculated and it was obtained in two angles, namely \pm $39.5^{\circ}$ and $\pm 140.5^{\circ}$. So, the strain gauges should be installed at an angle of $\pm 39.5^{\circ}$ and \pm 
$140.5^{\circ}$ from the top point of the ring section to measure $F_{h}$ without any side effects from $F_{v}$.

Based on the Hooke's Law on the elastic deformation, that the stress-strain relationship can be written by:

$$
\sigma=E \varepsilon
$$

where $\sigma$ is the stress, $E$ is the modulus of elasticity, and $\varepsilon$ is the strain. The maximum stress occurs due to a moment force is defined as:

$$
\begin{aligned}
& \sigma_{c}=\frac{M c}{I} \\
& I=\frac{b t^{3}}{12} ; c=\frac{t}{2}
\end{aligned}
$$

where $M$ is the moment, $c$ is the distance from the neutral axis to the edge of the structure, $I$ is the moment of inertia of the structure, $b$ is the width of the structure, and $t$ is the thickness of the structure. By substituting the equations (8) and (9) into the equation (7), the relationship between the strain and the applied force can be attained as:

$$
\varepsilon=\frac{\sigma}{E}=\frac{6 M}{E b t^{2}}
$$

where $M$ is the moment in the position of the angle, $\phi$. If the angular positions of the strain gauge nodes $\left(\phi=39.54^{\circ}\right.$ and $\left.90^{\circ}\right)$ are substituted in equation (3), then the following are obtained:

$$
\begin{aligned}
& M_{39.5^{\circ}}=0.386 F_{h} r \\
& M_{90^{\circ}}=-0.182 F_{V} r
\end{aligned}
$$

By substituting equations (11) and (12) into equation (10), the following are obtained:

$$
\begin{gathered}
\varepsilon_{h}= \pm \frac{2.32 F_{h} r}{E b t^{2}} \\
\varepsilon_{V}= \pm \frac{1.09 F_{V} r}{E b t^{2}}
\end{gathered}
$$

In order to avoid structural failure due to overload, the maximum stress on the transducer must be below the yield strength of the structural material. By taking into account the safety factor of 1.3 , the maximum allowable stress can be obtained through the following:

$$
\sigma_{\max }=\frac{S_{y}}{s f}
$$

where $S_{y}$ is the yield strength of the material structure, and $s f$ is the safety factor. When stainless steel 304, with yield strength of $205 \mathrm{MPa}$, was selected as the transducer material, then the allowable maximum stress was:

$$
\sigma_{\max }=\frac{205}{1.3}=158 \mathrm{MPa}
$$

Then, by considering equations (7) and (16), equations (13) and (14) became:

$$
\begin{aligned}
& F_{h} \max =\frac{68.1 b t^{2}}{r} \\
& F_{V} \max =\frac{144.95 b t^{2}}{r}
\end{aligned}
$$


In order to determine the maximum force that was applied to the octagonal ring, the geometrical dimensions of the transducer were obtained from equations (17) and (18) as follows:

$$
\begin{aligned}
& F_{h} \max =\frac{68.1(15)(3)^{2}}{12.5}=735.48 \mathrm{~N} \\
& F_{V} \max =\frac{144.95(15)(3)^{2}}{12.5}=1565.46 \mathrm{~N}
\end{aligned}
$$

Since the force occurred on the top plate of the dynamometer, which was supported by the four octagonal rings, so the total maximum force of the dynamometer was about $2900 \mathrm{~N}$. This was the maximum force that could be accepted by the strain gauge-based dynamometer within safe limits.

\section{Mathematical analysis of the dynamic properties}

The dynamic response analysis is an important data in design and development a turning dynamometer because it would be subjected to the dynamic cutting force when it was used in turning operation. When dynamic or a cyclic force is applied to the dynamometer structure, causing the vibration and generate a frequency response. The chatter can occur when one or more of the frequencies of the cyclic force and dynamic cutting force are equal or close to one or more natural frequencies of the dynamometer structure [10]. A natural frequency of the developed dynamometer should have at least four times the vibration frequency of the machine tool to ensure machining stability [11]. The excitation frequency is generated from machine tool has a correlation to the spindle speed $(n \mathrm{rpm})$, which can be expressed as follows [11]:

$$
f_{e}=\frac{n}{60}(\mathrm{~Hz})
$$

This dynamometer was designed for the application of a spindle speed below of $5000 \mathrm{rpm}$, so the exciting frequency of the machine tool was:

$$
f_{e}=\frac{5000}{60}=83 \mathrm{~Hz}
$$

Therefore, minimal natural frequency of the dynamometer was:

$$
f \geq 4 \times 83 \mathrm{~Hz}=333.33 \mathrm{~Hz}
$$

In theoretical dynamic analysis of the strain-gauge based dynamometer, the stiffness of the structural material had to be determined based on the relationship of force and displacement. The elastic structure can be analogous as a simple spring model, so the force is a function of the displacement of structure which can be written as:

$$
F=k(x)
$$

where $F$ is the external force $(\mathrm{N}), k$ is the stiffness of structure or spring constant $(\mathrm{N} / \mathrm{m})$ and $x$ or $\delta$ is the displacement $(\mathrm{m})$. The stiffness of the designed force transducer depended on the directions of the applied forces on the structure and also its material and geometry. The stiffness of an octagonal ring is given as in the following equations [11]

$$
\begin{aligned}
& k_{V}=\frac{F_{V}}{\delta_{V}}=\frac{E b t^{3}}{1.8 r^{3}} \\
& k_{h}=\frac{F_{h}}{\delta_{h}}=\frac{E b t^{3}}{3.6 r^{3}}
\end{aligned}
$$

By substituting all the geometrical parameters of the octagonal ring design into equations (21) and (22), the following were obtained: 


$$
\begin{aligned}
& k_{V}=\frac{193000(15)(3)^{3}}{1.8(12.5)^{3}}=22233 \mathrm{~N} / \mathrm{mm} \\
& k_{h}=\frac{193000(15)(3)^{3}}{3.6(12.5)^{3}}=11116 \mathrm{~N} / \mathrm{mm}
\end{aligned}
$$

Since the force occurred on the top plate of the dynamometer, which was supported by four octagonal rings in a parallel arrangement, the stiffness in the vertical and horizontal directions were $88932 \mathrm{~N} / \mathrm{mm}$ and $44464 \mathrm{~N} / \mathrm{mm}$, respectively.

The natural frequency of the dynamometer, which was assumed to be a small mass supported by the ring elements, was obtained from the following relationship [11]:

$$
f=\frac{1}{2 \pi} \sqrt{k / m}
$$

where $k$ is the stiffness of the octagonal ring $(\mathrm{N} / \mathrm{m}), m$ is the mass front plate of dynamometer $(\mathrm{kg})$, and $f$ is the natural frequency $(\mathrm{Hz})$ of the dynamometer.

From the design and construction of the dynamometer, it was found that the weight of the force transducer and its supported components was $1.925 \mathrm{~kg}$. So, the natural frequencies of the strain-gauge based dynamometer were calculated as:

$$
\begin{aligned}
& f_{F_{v}}=\frac{1}{2 \pi} \sqrt{k_{F_{c}} / m}=\frac{1}{2 \times 3.14} \sqrt{\frac{88932 \times 1000}{1.925}}=1082.3 \mathrm{~Hz} \\
& f_{F_{h}}=\frac{1}{2 \pi} \sqrt{k_{F_{t}} / m}=\frac{1}{2 \times 3.14} \sqrt{\frac{44464 \times 1000}{1.925}}=765.3 \mathrm{~Hz}
\end{aligned}
$$

It was found that frequency minimum is four time of machine tool frequency that is 765.3 Hz. Therefore, the dynamometer structure that had been designed met the safety factor requirements.

\section{FEM analysis of the force transducer}

In order to analysis the stress and strain distributions, ANSYS was used to perform a static analysis on the force transducer and dynamometer, which were subjected to a force in two directions, vertical and horizontal. Figure 4 shows the finite element mesh of the stress and stress distributions on the octagonal ring force transducer and dynamometer. The force that was applied in a vertical and horizontal direction was equivalent to approximately $1000 \mathrm{~N}$. A deformation analysis was performed, and normal stress distributions occurred on the surface of the octagonal ring force transducer due to the horizontal force, and a strain occurred when the vertical force was applied, as shown in Fig 3. It can be seen that stress occurred on the surface of the transducer due to the horizontal force, and the strain that occurred was about 145-241 MPa. This result was consistent with the mathematical analysis, which obtained a result of about $214 \mathrm{MPa}$. On the other hand, the strain due to the vertical force on the side surface of the transducer was within the range of $4.5 \times 10^{-4}$ to $6 \times 10^{-4} \mathrm{~mm} / \mathrm{mm}$. This result was in agreement with the mathematical analysis, which showed that the strain on the side surface was $5.2 \times 10^{-}$ ${ }^{4} \mathrm{~mm} / \mathrm{mm}$. These findings have important implications as they indicate that the design analysis of the octagonal ring force transducer based on theoretical and FEM approaches was accurate. 

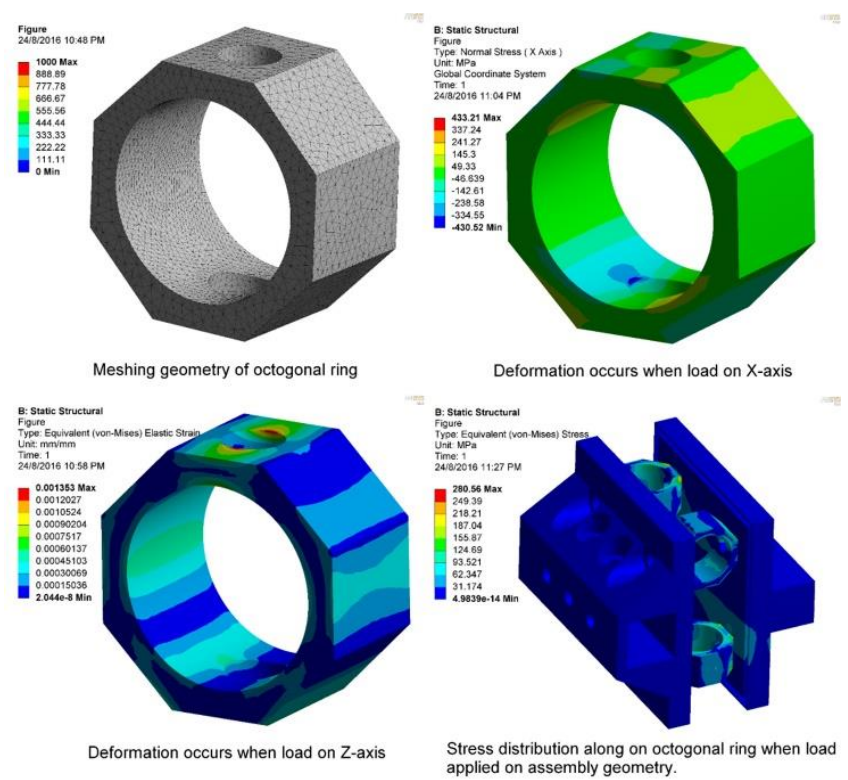

Figure 4. Stress and strain distribution on the surface of the octagonal ring and developed dynamometer

\section{Arrangement of strain gauges}

The stress and strain on the surface of the material will change when an external load or force is applied to the structure of force transducer. The strain can be detected by strain gauge and then converted into voltage signals that represent the applied force to the structure. Resistance of strain gauge will change to reflect the change in stress due to the applied load or force. The ratio of relative change in strain gauge resistance to the actual mechanical strain is called as the gauge factor, which can be written as [12]:

$$
G F=\frac{\Delta R / R}{\Delta L / L}=\frac{\Delta R / R}{\varepsilon}
$$

where $R$ is the original resistance of the strain gauge (ohm), $L$ is the original length of structure $(\mathrm{mm})$, and $\varepsilon$ is the mechanical strain $(\mathrm{mm} / \mathrm{mm})$.

By consider the results of FEM analysis, there are three orientations of strain gauge locations in the structure of a dynamometer structure for measuring the cutting force in the direction of the $x, y$ and $\mathrm{z}$ coordinates. Figure 5 shows the mounted locations of the strain gauges on the octagonal ring for detection three directions of the force components. A full Wheatstone bridge circuit was used for each channel, as shown in Figure 6.
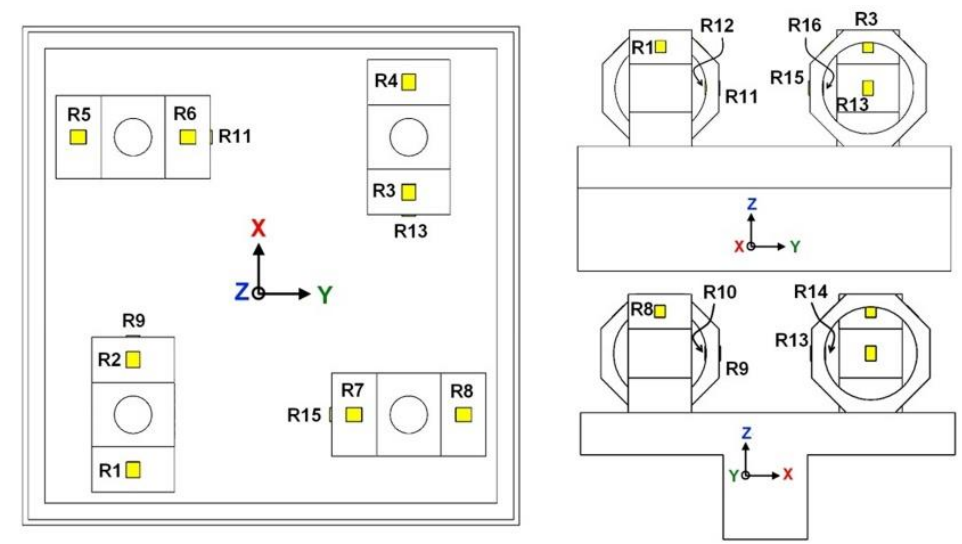

Figure 5. Location of strain gauges on four octagonal rings in a dynamometer 


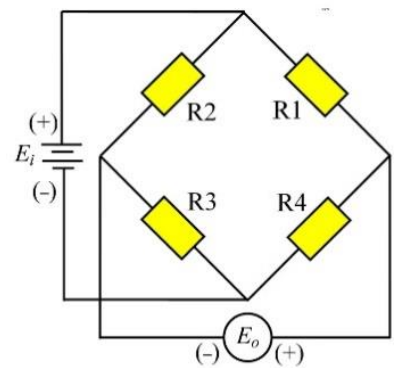

(a)

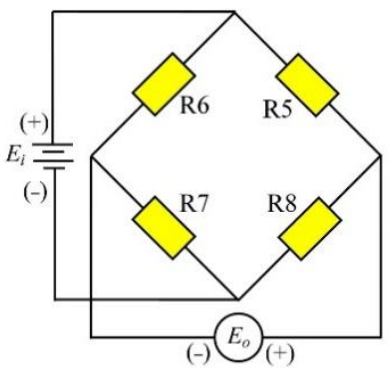

(b)

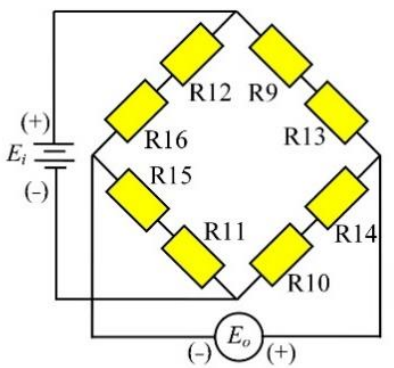

(c)

Figure 6. Strain gauge arrangement on Wheatstone bridges circuit: (a) channel on $F_{x}$; (b) channel on $F_{y}$; and (c) channel on $F_{z}$.

The arrangement of the strain gauges for detecting the force in the $x$ direction or the main cutting force. $F_{c}$ is described in Figure $6(\mathrm{a})$. The strain gauges R1 and R3 were subjected to tensile stress, while R2 and R4 were subjected to compressive stress, respectively. The force in the $y$ direction or the radial force, $F_{r}$ was detected by R6 and R8, where these strain gauges were subjected to compressive stress, as shown in Fig. 6(b), while R5 and R7 were subjected to tensile stress. The force in the $z$ direction or the feed force, $F_{f}$ was supported by four octagonal rings with the arrangement of strain gauges as shown in Figure 6(c). Compressive stress was exerted on strain gauges R10, R12, R14 and R16, while the strain gauges R9, R11, R13 and R15 were subjected to tensile stress. A general purpose-type strain gauge from Omega (SGD-3/350-LY11) was used for three orientations of coordinate with the nominal resistance of each strain gauge being 350 $\mathrm{Ohm}$. The gauges had a gauge factor of 2.14 , length of $3 \mathrm{~mm}$, and width of $3.2 \mathrm{~mm}$. The equation for converting the rated strain from the theoretical analysis $(\mu \mathrm{m} / \mathrm{m})$ into the rated output value for the voltage signal $(\mathrm{mV} / \mathrm{V})$ is as follows:

$$
\frac{V_{o}}{V_{i}}=\frac{1}{4} G F \varepsilon
$$

where $V_{i}$ is the input voltage, $V_{o}$ is the output voltage of the Wheatstone bridge, $G F$ is the gauge factor of the strain gauge, and $\varepsilon$ is the strain rate from the theoretical analysis.

\section{Construction and fabrication of the strain gauge-based dynamometer}

The construction of the strain gauge-based dynamometer that was developed for the turning process is shown in Figure 7. The complete structure comprised a bottom plate, a top plate and four octagonal rings. The four octagonal rings were attached between the bottom and top plates. The dynamometer was clamped to the tool post of a lathe machine using a rectangular beam at the back of the bottom plate. All the structural components of the dynamometer were fabricated by using machining process on stainless steel grade 304. Figure 7 shows the photograph of the complete strain gauge-based dynamometer developed for turning. The cutting force signals coming from the strain gauge in the dynamometer were conditioned, amplified and logged by a data acquisition system (NI 9237). LabView software was used for acquisition, visualization and signal processing the collected signals. 


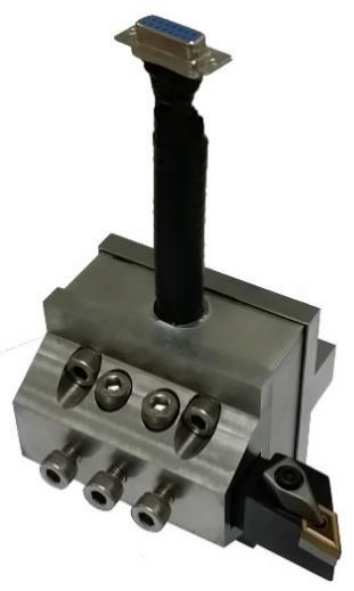

Figure 7. Photograph of the complete dynamometer

\section{TESTING OF STRAIN GAUGE-BASED DYNAMOMETER}

\section{Calibration test}

In order to determine the relationship between the input and output data, a calibration test was performed. It is also to investigate the performance and sensitivity of dynamometer after design and construction. A calibration fixture was used as shown in Figure 8 . The calibration was made in three directions or coordinates for $F_{c}$ (x-axis), $F_{r}$ ( $y$-axis) and $F_{f}$ (z-axis) for an applied load of up to $1000 \mathrm{~N}$, with incremental steps of $50 \mathrm{~N}$. At each applied load interval, the reading of the output was averaged and recorded. Then, the curves of static calibration were obtained and the raw signal in voltage reading can be converted to the force values in Newton.

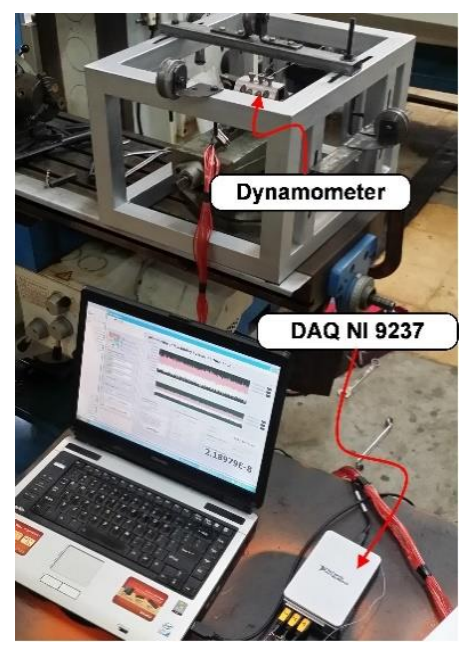

Figure 8. Calibration setup for developed dynamometer

The calibration tests were repeated three times to ensure the consistency, and the average values were recorded. Figure 9 shows the calibration curves for the main cutting force $F_{c}$, the radial force $F_{r}$ and the feed force $F_{f}$, respectively. The calibration matrix from the static calibration results was obtained as follows: 


$$
C_{\text {Exp. }}=\left[\begin{array}{ccc}
31.3 & 2.1 & 3.0 \\
1.5 & 172.4 & 2.3 \\
1.7 & 3.0 & 61.5
\end{array}\right]
$$
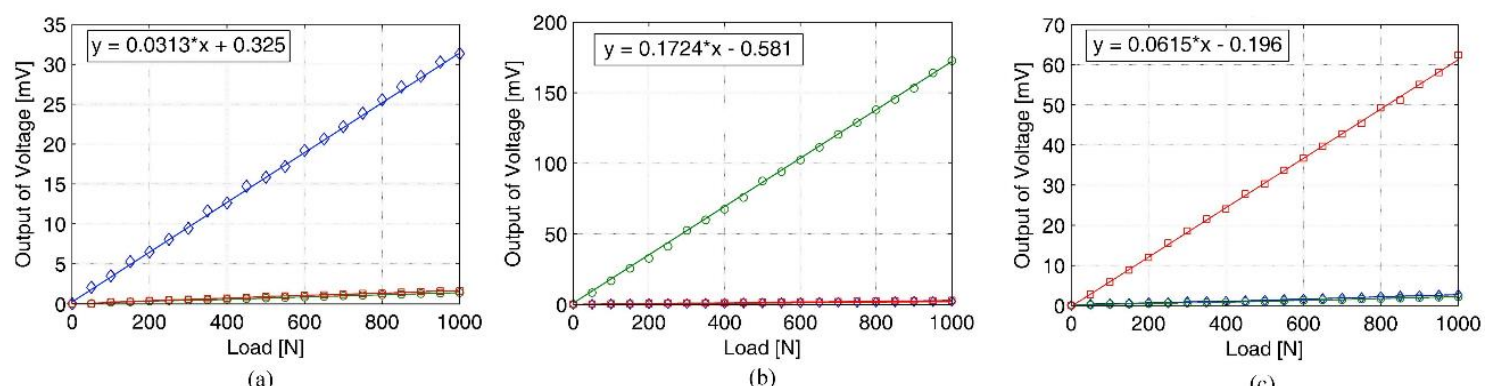

(c)

Figure 9. The dynamometer calibration: (a) $x$-axis; (b) $y$-axis; (c) $z$-axis

It was obvious from the calibration curves and the matrix that the sensitivities of the strain gauge-based dynamometer that were obtained were about $31.3 \times 10^{-3} \mathrm{mV} / \mathrm{N}$, $172.4 \times 10^{-3} \mathrm{mV} / \mathrm{N}$ and $61.5 \times 10^{-3} \mathrm{mV} / \mathrm{N}$. Table 1 shows the cross-sensitivity errors for the $F_{c}, F_{r}$ and $F_{f}$ directions. The maximum error of $9.58 \%$ was shown in the $F_{c}$ component in the $F_{f}$ direction, while the error in the other components did not exceed $5 \%$, and even in the radial direction it was only $0.87 \%$. This means that the developed dynamometer is acceptable for use in the measurement of the cutting force and the result in good accordance with other cutting force measurements performed by the previous authors [7, 13].

Table 1. Cross-sensitivity error of dynamometer based on calibration test

\begin{tabular}{cccc}
\hline \multirow{2}{*}{ Force direction } & \multicolumn{3}{c}{ Cross-sensitivity error $(\%)$} \\
\cline { 2 - 4 } & $F_{c}$ & $F_{r}$ & $F_{f}$ \\
\hline$F_{c}$ & - & 6.71 & 9.58 \\
$F_{r}$ & 0.87 & - & 1.33 \\
$F_{f}$ & 2.76 & 4.87 & - \\
\hline
\end{tabular}

In order to test the linearity of dynamometer, the results data from static calibration as shown in Fig 9 can be calculated to obtained the linearity error when maximum load about $1000 \mathrm{~N}$ was applied on dynamometer. The output reading of dynamometer and calibration values are shown in Table 2. It was found that the percentage error in $F_{c}, F_{r}$ and $F_{f}$ were calculated as $0.95 \%, 0.49 \%$ and $1.91 \%$ respectively.

Table 2. Linearity error of dynamometer based on calibration test

\begin{tabular}{cc|c|c}
\hline $\begin{array}{c}\text { Axes or Force } \\
\text { direction }\end{array}$ & $\begin{array}{c}\text { Output from } \\
\text { dynamometer }(\mathrm{mV})\end{array}$ & $\begin{array}{c}\text { Calibration } \\
\text { value }(\mathrm{mV})\end{array}$ & $\begin{array}{c}\text { Linearity } \\
\text { error }(\%)\end{array}$ \\
\hline$F_{c}$ & 31.323 & 31.625 & 0.95 \\
$F_{r}$ & 172.67 & 171.82 & 0.49 \\
$F_{f}$ & 62.47 & 61.13 & 1.91 \\
\hline
\end{tabular}

The developed dynamometer has been conducted the eccentricity test for evaluation the reading performance that give same output value when load was applied along the 
tool holder surfaces. The force $100 \mathrm{~N}$ was applied to the dynamometer at centre and at eccentricity distance (e) about $40 \mathrm{~mm}$ along y-axis. The eccentricity test results as shown in Table 3. It was found that the percentage of output error for $F_{c}, F_{r}$ and $F_{f}$ were $1.85 \%$, $2.59 \%$ and $1.22 \%$.

Table 3. Eccentricity error of dynamometer

\begin{tabular}{cc|c|c}
\hline $\begin{array}{c}\text { Axes or Force } \\
\text { direction }\end{array}$ & $\begin{array}{c}\text { Signal at force on the } \\
\text { centre point }(\mathrm{mV})\end{array}$ & $\begin{array}{c}\text { Signal at force on the } \\
\mathrm{e}=40 \mathrm{~mm}(\mathrm{mV})\end{array}$ & $\begin{array}{c}\text { Eccentricity } \\
\text { error }(\%)\end{array}$ \\
\hline$F_{c}$ & 3.132 & 3.174 & 1.85 \\
$F_{r}$ & 17.267 & 16.831 & 2.59 \\
$F_{f}$ & 6.247 & 6.324 & 1.22 \\
\hline
\end{tabular}

In order to evaluate the performance of dynamometer to measure resultant force, a force $35 \mathrm{~N}$ was applied in inclined $45^{\circ}$ from the point of centre the dynamometer. The output reading of dynamometer as shown in Figure 10. It was obviously that the component of force in $F_{c}, F_{r}$ and $F_{f}$ were $25 \mathrm{~N}, 15 \mathrm{~N}$ and $18 \mathrm{~N}$ respectively. So, it can be obtained that resultant force was $34.3 \mathrm{~N}$, and the percentage of output error was calculate as $2.1 \%$.

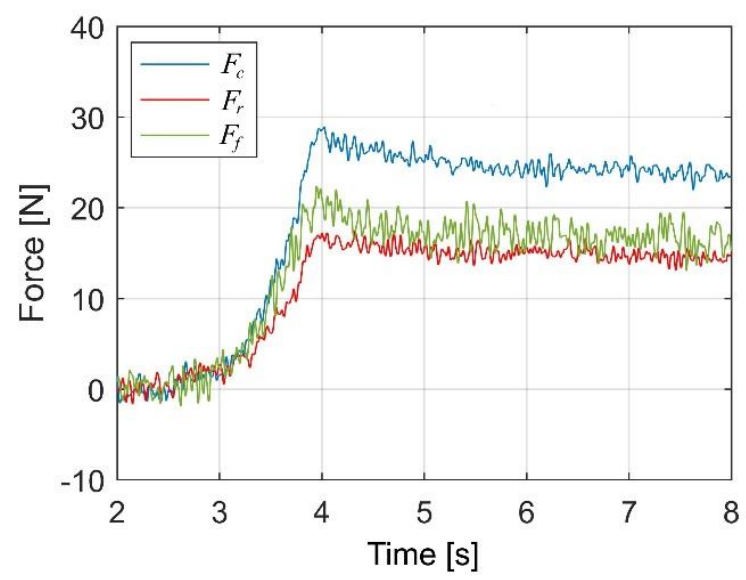

Figure 10. The force signal reading from performance test

The cutting force occurred in turning is always dynamic. So the system response of dynamic excitations should have been taken into consideration. The dynamic test has been conducted using a modal impact hammer Endevco type 3012, and an accelerometer (Endevco 751-100). Figure 11 show the frequency response curve for horizontal and vertical direction of dynamometer. It can be seen that the natural frequency are approximately $737 \mathrm{~Hz}$ and $1067 \mathrm{~Hz}$. When these results are compared to the theoretical analysis results, their error is less than $3.6 \%$. It means that the dynamic test and the theoretical calculation have a good agreement. 

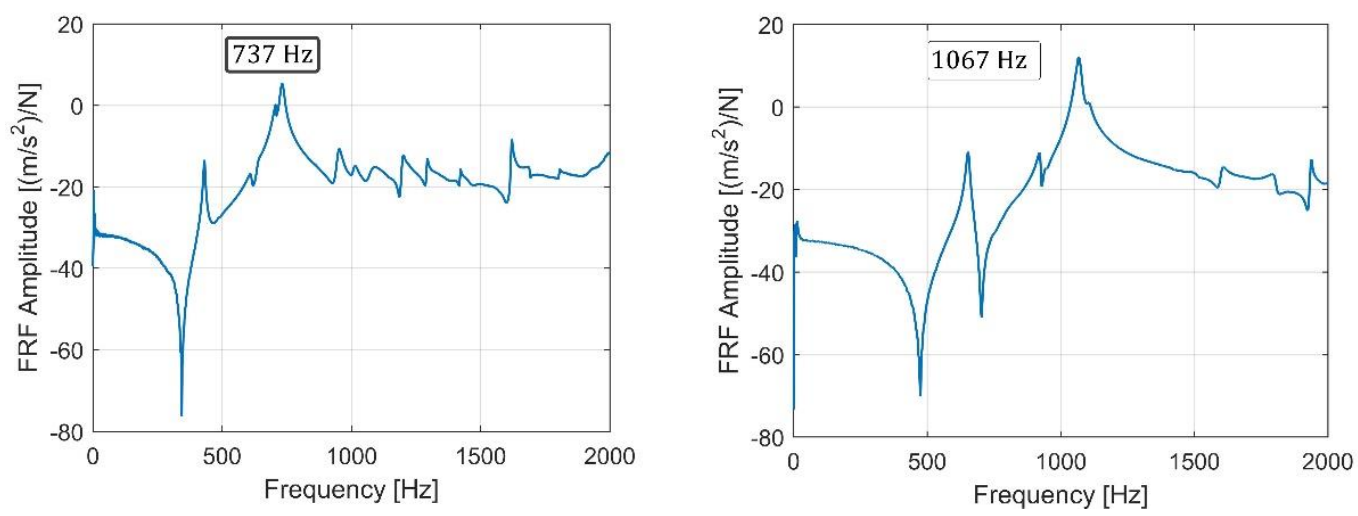

Figure 11. Frequency response in horizontal and vertical direction

\section{Machining test}

In order to evaluate the performance of the cutting force measurement using strain gaugebased dynamometer in a real turning operation, a machining test was performed using a conventional lathe machine under dry cutting conditions. AISI 1040 steel bar with $45 \mathrm{~mm}$ diameter was selected as workpiece material. The cutting tool insert is a coated tungsten carbide (Sumitomo DNMG150408N-UX) grade AC700G. These experiments were performed using a depth of cut $(a)$ of $1 \mathrm{~mm}$, feed rate $\left(f_{z}\right)$ of $0.2 \mathrm{~mm} / \mathrm{rev}$, cutting speed $\left(v_{c}\right)$ of $100 \mathrm{~m} / \mathrm{min}$, and machining setup as shown in Figure 10 . The cutting forces signal were measured at a sampling rate of $2 \mathrm{kHz}$. The experimental test was repeated in three time to evaluate the consistence of cutting force signal reading. The machining setup force cutting force measurement is given in Figure 12.

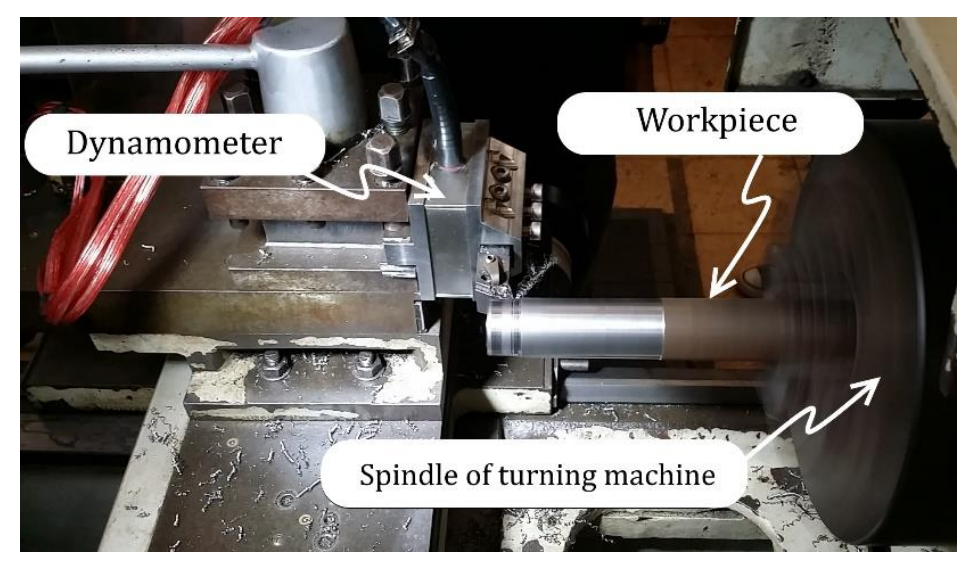

Figure 12. Machining test setup to evaluate the performance of the dynamometer

Figure 13 shows the result of cutting force measurement. It was clearly that the main cutting force $\left(F_{c}\right)$ was the highest cutting force in the turning process. This force occurred when the cutting tool sheared the workpiece in the tangential direction or parallel to the spindle rotation. The radial force $\left(F_{r}\right)$ was appear due to thrust of workpiece to the tool. This force is affected by the geometry of cutting tool. Whereas the feed force is greatly influenced by feed motion of the cutting tool. According to the Figure 13, the results of the measured cutting forces were $11 \mathrm{~N}, 6 \mathrm{~N}$ and $3 \mathrm{~N}$ for $F_{c}, F_{r}$ and $F_{f}$, respectively. In addition, it was observed from the pattern of the cutting force signal that the time of engagement between the cutting tool and the workpiece was obviously visible 
in the very apparent signals. This means that the developed dynamometer can sense the forces properly.
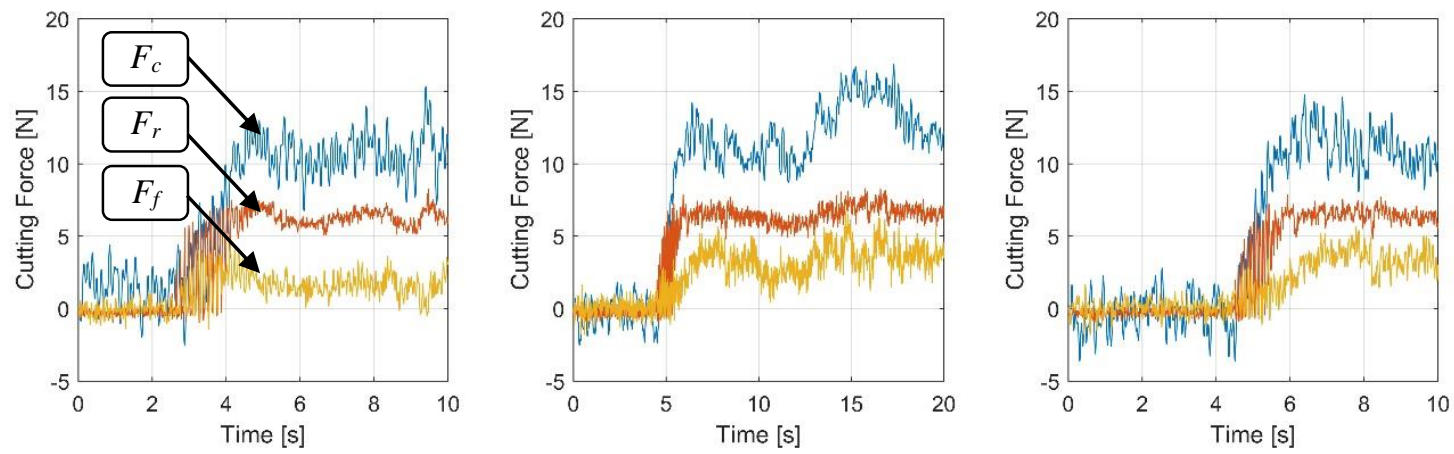

Figure 13. The cutting force signal during three time of turning processes

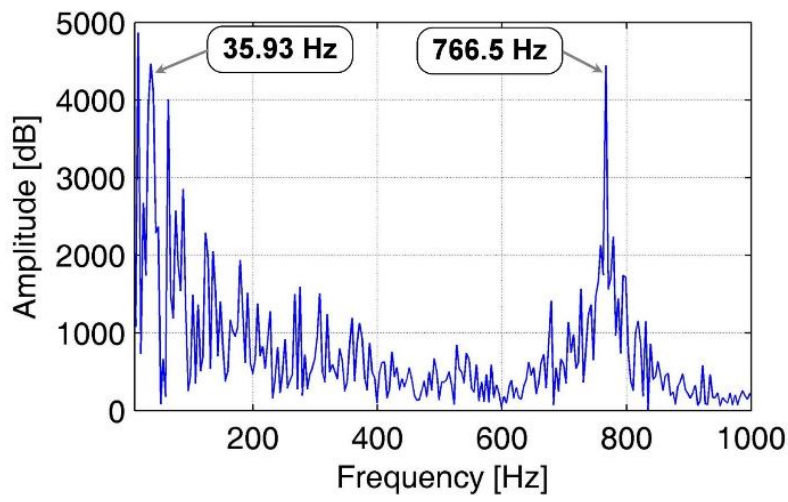

Figure 14. Tool passing frequency in turning

Figure 14 shows the tool passing frequency (TPF) and the structure frequency during machining. It can be seen that the frequencies that appeared on the signal were about $35.95 \mathrm{~Hz}$ and $766.5 \mathrm{~Hz}$. These results showed that the developed dynamometer was able to detect the dynamic signal of the cutting force, and this means that the system was in good agreement with the theoretical analysis, which found that the natural frequency of the structure was about $765.3 \mathrm{~Hz}$. It is encouraging to compare this results with that found by Totis el al. [13] who found the developed dynamometer have dynamic response in range $500-1000 \mathrm{~Hz}$.

Generally, the developed dynamometer is reliable as a measurement system. This system is an alternative method for the measurement of the cutting force that can be applied in a turning process. It can be implemented on an automation system in tool condition monitoring (TCM). In addition, the strain gauge-based dynamometer can also be used to investigate machinability, parameter optimizations and tool condition monitoring system in turning process.

\section{CONCLUSION}

Development of a triaxial dynamometer for the turning process has been presented. The device is easy mounted on the tool post or turret of lathe machine and not invasive. It system capable for measurement of the tangential cutting force or main cutting force, the feed force and the radial force. The geometrical design of the dynamometer is such that the tool shank is interchangeable to provide a flexible and reconfigurable machining 
process. The maximum measurement of cutting force is about $2900 \mathrm{~N}$ and has a dynamic response of about $766 \mathrm{~Hz}$. The results of calibration and machining tests showed that its sensitivity was approximately in the range of $31.3 \times 10^{-3}-172.4 \times 10^{-3} \mathrm{mV} / \mathrm{N}$ and it has a low cross-sensitivity error of below $0.87 \%$. The developed system gave a satisfactory performance and it has the potential to be used in actual industrial and institutional applications.

\section{ACKNOWLEDGEMENTS}

The authors would like to thank Syiah Kuala University for its financial support under grant 1712/UN11/SP/PNBP/2016, and Universiti Kebangsaan Malaysia for its financial support under grant FRGS/1/2016/TK03/UKM/01/1.

\section{REFERENCES}

[1] Tahir MASM, Ghani JA, Nuawi MZ, Rizal M, Haron CHC. Flank wear and I-kaz 3D correlation in ball end milling process of Inconel 718. Journal of Mechanical Engineering and Sciences. 2015;9:1595-603.

[2] Rizal M, Ghani JA, Nuawi MZ, Haron CHC. Development and testing of an integrated rotating dynamometer on tool holder for milling process. Mechanical Systems and Signal Processing. 2015;52-53:559-76.

[3] Scheffer C, Heyns PS. An industrial tool wear monitoring system for interrupted turning. Mechanical Systems and Signal Processing. 2004;18:1219-42.

[4] Rizal M, Ghani JA, Nuawi MZ, Haron CHC. Online tool wear prediction system in the turning process using an adaptive neuro-fuzzy inference system. Applied Soft Computing. 2013;13:1960-8.

[5] Ghani JA, Rizal M, Nuawi MZ, Ghazali MJ, Haron CHC. Monitoring online cutting tool wear using low-cost technique and user-friendly GUI. Wear. 2011;271:2619- 24.

[6] Ghani JA, Jye PS, Haron CHC, Rizal M, Nuawi MZ. Determination of sensor location for cutting tool deflection using finite element method simulation. Proceedings of the Institution of Mechanical Engineers, Part C: Journal of Mechanical Engineering Science 2012;226:2373-7.

[7] Yaldız S, Ünsaçar F. A dynamometer design for measurement the cutting forces on turning. Measurement. 2006;39:80-9.

[8] Panzera TH, Souza PR, Rubio JCC, Abrão AM, Mansur TR. Development of a three-component dynamometer to measure turning force. International Journal of Advanced Manufacturing Technology 2012;62:913-22.

[9] Wang C, Cheng K, Minton T, Rakowski R. Development of a novel surface acoustic wave (SAW) based smart cutting tool in machining hybrid dissimilar material. Manufacturing Letters. 2014;2:21-5.

[10] Liu X. Machining Dynamics in Milling Processes. In: Cheng K, editor. Machining Dynamics: Fundamentals, Applications and Practices Springer; 2009. p. 167-231.

[11] Shaw MC. Metal Cutting Principle. 2nd ed. New York: Oxford University Press; 2005.

[12] Figliola RS, Beasley DE. Theory and Design for Mechanical Measurements. Third ed. New York: John Wiley \& Sons, Inc.; 2000. 
[13] Totis G, Sortino M. Development of a modular dynamometer for triaxial cutting force measurement in turning. International Journal of Machine Tools \& Manufacture. 2011;51:34-42. 